\title{
El figuralismo como un modelo estético de interpretación histórica: análisis de la figura de "hijo de desaparecido"
}

\author{
Figuralism as an Aesthetic Model of Historical Interpretation: an \\ Analysis of the "Child of Desaparecido" Figure
}

\author{
Omar Murad \\ muradoma@gmail.com \\ Professor \\ Universidad Nacional de Mar del Plata \\ Chaco 1235, Mar del Plata \\ B7600BKY - Buenos Aires \\ Argentina
}

\section{Resumen}

En este trabajo utilizaremos la noción de "figuración" para dar cuenta de la intervención específica de los hijos de desaparecidos de la última dictadura argentina en el ámbito del discurso de la memoria. Sugerimos que esta comprensión estética del acontecer histórico permite aproximarnos fructíferamente al análisis de las representaciones del pasado reciente elaboradas por los hijos de desaparecidos de la referida dictadura. En efecto, dada la figura del desaparecido, el hijo de desaparecido puede ser considerado como el cumplimiento de esta figura. Finalmente analizamos dos documentales que nos permiten contrastar ésta sugerencia.

\section{Palabras clave}

Filosofía da historia; Memoria; Virada subjetiva.

\begin{abstract}
In this work I resort to the notion of "Figuralism" to account for the specific intervention of the children of the desaparecidos of the past Argentine dictatorship, in the field of memory discourse. I suggest that this aesthetical understanding of historical events allow us to productively analyze the representations of the children of the desaparecidos of Argentina's recent past. Indeed, when one considers the figure of the desaparecidos, the children of the desaparecidos can be seen as the fulfillment of this figure. Finally, I analyze two documentary films that allow us to corroborate this suggestion.
\end{abstract}

\section{Keywords}

Philosophy of history; Cultural memory; Subjective turn.

Recibido en: 20/8/2014

Aprobado en: 9/12/2014

\footnotetext{
* Este artículo ha contado con el apoyo financiero del Consejo Nacional de Investigaciones Científicas y Técnicas (CONICET).
} 
En este trabajo, utilizaremos la noción de "figuración" para dar cuenta de la intervención específica de los hijos de desaparecidos de la última dictadura argentina en el ámbito del discurso de la memoria. La figuración nos provee de un modelo estético de interpretación histórica que puede ser fructíferamente utilizado en el análisis de las representaciones del pasado reciente argentino elaborado por la generación de hijos de desaparecidos. Nuestra sugerencia es que, más allá del lazo biológico, siguiendo este modelo estético podemos ver la figura del "hijo de desaparecido" como el cumplimiento de la figura de "desaparecido".

Para realizar esta tarea dividiremos este trabajo en tres apartados. Comenzaremos esbozando la noción de figuralismo elaborada por Hayden White para acentuar su capacidad de relacionar retrospectivamente acontecimientos por medios estéticos. En el segundo apartado, reconstruiremos dos modalidades del discurso de la memoria del pasado reciente argentino con el fin de contextualizar la emergencia de la figura de "desaparecido" y la de "hijo de desaparecido". Finalmente, en el último apartado, analizaremos dos documentales pertenecientes a hijos de desaparecidos con el fin de contrastar nuestra sugerencia.

\section{Figuralismo}

En Figural Realism Hayden White vuelve sobre una cuestión presente en su obra al menos desde principios de los años 1970: el figuralismo. El uso de esta noción en la obra de White se remonta a 1972, cuando publica ¿Qué es un sistema histórico?, o, aún antes, a 1967, cuando ese texto es presentado en Denver en forma de conferencia. Indistintamente, White atribuye a Auerbach o a Nietzsche la idea de que el cambio histórico consiste en la substitución del pasado genético del cual realmente descendemos por el pasado histórico del cual querríamos descender (WHITE 2011, p. 14; WHITE 2010a, p. 33-52). Así, en "La historia Literaria de Auerbach. Causalidad figural e historicismo modernista", incluso nos habla de un "modelo estético" que informa el opus magnum de Auerbach: Mimesis. Según nuestro punto de vista, es importante destacar - con White que en los sistemas históricos se reemplaza la herencia biológica de los agentes involucrados por antepasados ideales. De allí que posee una "plasticidad" que excede las posibilidades de los "sistemas biológicos" (WHITE 2011, p. 260). En los sistemas históricos, los agentes tienen la capacidad de actuar "como si pudieran elegir sus antepasados" a partir de una sustitución retroactiva de antepasados en la cual los agentes actúan como si descendieran de modelos históricos o míticos en lugar de hacerlo de su propia herencia genética (WHITE 2011 , p. 260). Esto implica, entra otras cosas, que los agentes son capaces de elegir sus antepasados ideales según los recursos simbólicos disponibles en su dotación cultural. Y lo hacen en función de los conflictos que son propios de cada sociedad. En palabras de White:

Esta sustitución retroactiva de antepasados, que representa un ingrediente esencial para la constitución de los sistemas históricos, está marcada por el hecho de que cada sociedad reconoce la clase de conflictos que les ocasiona a los individuos y trata de brindarles medios para sublimarlos (WHITE 2011, p. 260). 
Un ejemplo dado por el mismo White - que sigue de cerca al ensayo "Figura" de Auerbach (1998), una de la "fuentes" de las que él mismo se sirve para desarrollar su noción de figuralismo - es el abandono de la civilización romana y la constitución de la civilización medieval-cristiana. No hay nada en la herencia genética de los antiguos romanos que hiciera que su sociedad desapareciera. De hecho, en Europa occidental desapareció antes que en oriente, en Bizancio. La respuesta a la pregunta cuándo dejó de existir el sistema sociocultural romano es: cuando los habitantes de Europa occidental reconocieron en la herencia judeocristiana su propio pasado. Dice White:

Lo que sucedió entre los siglos III y VIII fue que los hombres dejaron de considerarse como descendientes de sus antepasados romanos y empezaron a considerarse descendientes de sus predecesores judeocristianos (WHITE 2011, p. 259, destacado del original).

De modo que la "plasticidad" mentada responde a un modelo estético que permite vincular imaginativamente un acontecimiento pasado con un estado de cosas presente. Este modelo es "estético" no porque esté ligado de alguna manera a consideraciones sobre el arte o la belleza, sino porque utiliza la imaginación y su capacidad de realizar síntesis entre cosas disímiles estableciendo relaciones allí donde aparentemente no hay ninguna.

En consideraciones posteriores sobre el figuralismo, White señala otra característica del mismo, esta vez poniéndolo en relación con la "genealogía" nietzscheana y foucaultiana. Nos dice que el figuralismo opera al igual que aquella que, anclada en el presente, establece retroactivamente relaciones causales con un estado de cosas pasado. White llama "causalidad figural" a la capacidad de las figuras de contener la expectativa de su cumplimiento futuro - es decir, de prefigurarlo -, la cual sólo puede ser dilucidada a partir de su realización en el presente. La relación causal entre la figura y su realización sólo puede ser conocida retrospectivamente, del mismo modo que la promesa sólo puede ser inferida de su cumplimiento, pero el cumplimiento no puede ser inferido de la promesa (WHITE 2010a, p. 36). El cumplimiento funciona aquí como una siempre renovada promesa de realización y provee de un "equivalente moderno de telos clásico" y un "equivalente secular de apocalipsis cristiano", dota "a la historia de un significado de progressus hacia una meta nunca plenamente realizable" (WHITE 2010a, p. 35, destacado del original). Difiere, pues, tanto de las antiguas nociones teleológicas como del mecanicismo científico moderno, aún cuando ésta sea una diferencia sutil. Señala White:

La misma [causalidad figural] informa el proceso por medio del cual la humanidad se auto realiza por medio de su capacidad singular de cumplimentar las múltiples figuras en y por medio de las cuales la realidad es, a un mismo tiempo, representada como un objeto para la contemplación y como un premio, un pretium, un objeto de deseo digno de los esfuerzos humanos por comprenderlo y controlarlo (WHITE 2010a, p. 35, destacado del original). 
Al igual que la promesa, la casualidad figural posee cierta performatividad en la medida en que la realización de la figura de un estado de cosas presente introduce un significado y un sentido en el mundo y la historia. Este significado no está ligado necesariamente a una base fáctica o a una relación necesaria entre los elementos relacionados, sino que es un producto de la libre elección de los agentes involucrados, quienes al volver significativo un estado de cosas presente utilizan al pasado para señalar el sentido del futuro. En ese mismo proceso, se dan a sí mismos una identidad que no está ligada necesariamente a su procedencia genética, sea cual sea esta. Al mismo tiempo, cada figura consumada contiene la promesa de una futura realización (prefiguración), de modo que la figura es renovada por los intérpretes en cada nuevo contexto. ${ }^{1}$

Ahora bien, ¿cómo podemos servirnos del modelo estético que ofrece el figuralismo para analizar el caso de los discursos de hijos de desaparecidos? Dado que, en principio, el vínculo que existe entre los desaparecidos y sus hijos es genético, parece natural relacionar a los últimos con sus predecesores como sus descendientes. Pero si tenemos en cuenta lo dicho más arriba sobre el figuralismo, bajo esta luz la relación entre padres e hijos aparecería como una de naturaleza ético-política - en tanto supone una elección - y no meramente biológica. En este sentido, el estudio de la figura de "hijo de desaparecido" bajo el supuesto de que se trata del cumplimiento de la figura de "desaparecido" implica analizar los elementos estéticos que la constituyen como tal. Reducir estos elementos a mera retórica u ornamentación o pensarlos sólo como ficciones equivale a obliterar el hecho de que pretenden referirse al mundo histórico e intervenir en él. Justamente el análisis de su construcción debería indicarnos la perspectiva desde la cual se interviene en un ámbito de discusión, así como los elementos discutidos dentro de dicho ámbito. Por ello, en lo que sigue, intentaremos dar cuenta del contexto de emergencia de la figura de "desaparecido" dentro de los discursos de la memoria de la última dictadura argentina para contextualizar, así, el surgimiento de la figura de "hijo de desaparecido".

\section{Dos modalidades de discurso de la memoria del pasado reciente en la Argentina}

Hay cierto consenso en distinguir esquemáticamente dos modalidades que asume el discurso sobre el pasado: el de la historia que "es una puesta en relato, una escritura del pasado según las modalidades y reglas de un oficio - de un arte o entre muchas comillas, de una ciencia - que intenta responder a las cuestiones que la memoria suscita" (TRAVERSO 2011, p. 21). Puesto de este modo, la historia sería la representación objetiva del pasado, busca conocerlo y

\footnotetext{
${ }_{1}^{1}$ Verónica Tozzi (2008) retoma la noción de figuralismo de Hayden White para destacar su productividad heurística, considerando cada escritura sobre el pasado como una promesa de nuevas reescrituras del pasado. En esta lectura es fundamental la consideración del "contexto" como el elemento que introduce la diferencia y "Ileva [a los intérpretes] a sugerir una nueva apropiación del pasado que se ofrece a su vez a las generaciones por venir para que se apropien a su vez de ella, pero que de manera obligada será reapropiada y así sucesivamente" (TOZZI 2008, p. 134).
} 
por ello está gobernada por imperativos epistemológicos. La otra modalidad del discurso sobre el pasado es la memoria, que se extrae de la experiencia vivida y, por ello, es eminentemente subjetiva. Señala Enzo Traverso que la memoria

\begin{abstract}
Está anclada en los hechos a los que hemos asistido, hechos de los que fuimos testigos, incluso actores, y a las impresiones que grabaron en nuestro espíritu. Es cualitativa, singular, se preocupa poco por las comparaciones, por la contextualización, por las generalizaciones. No necesita pruebas para aquel que es portador de ella. El relato del pasado que un testigo nos brinda - siempre y cuando este último no sea un mentiroso consciente - siempre será su verdad, o sea, la imagen del pasado depositada en él. Debido a su carácter subjetivo, la memoria jamás está fijada; se parece más bien a una obra abierta, en transformación permanente (TRAVERSO 2011, p. 22).
\end{abstract}

Debido a que el discurso de la memoria tiene una mayor libertad expresiva y está relativamente dispensado de ceñirse a hechos debidamente comprobados puesto que no se halla regulado por la práctica historiografía - , afirmamos que él está gobernado por imperativos estéticos y ético-políticos antes que epistemológicos. En cualquier caso, para historiadores como Enzo Traverso o Dominick LaCapra, las diferencias irreconciliables que pudieran surgir entre la historia y la memoria se pueden salvar a partir del reconocimiento de sus respectivas maneras de apropiarse del pasado, las cuales resultan complementarias y no meramente excluyentes (TRAVERSO 2011; LACAPRA 2005).

La memoria, además, está atravesada por las exigencias de justicia

190 y reparación y pone en crisis la tensión entre continuidad y discontinuidad histórica, es decir, el tipo de vínculo entre presente y pasado (MACÓN 2006, p. 13). En este sentido, como ha apuntado el historiador belga Berber Bevernage, la cronosofía occidental - con el acento puesto en la idea de un tiempo singular como un continuo infinito de instantes efímeros - conduce a una metafísica de lo presente y de lo ausente que opone y excluye presente y pasado (BEVERNAGE 2010, p. 183). La salida a este atolladero podría radicar en la admisión de una pluralidad de presentes y pasados fragmentarios y anacrónicos que se resisten a ser unificados. En cualquier caso, se trata de la emergencia de una nueva "consciencia histórica" que "exige diálogos permanentes y provisorios al interior de una comunidad" (MACÓN 2006, p. 22).

En la Argentina este proceso de "diálogo" se inició con el regreso de la democracia en diciembre del año 1983. En 1985 comenzó el juicio a la dictadura de las juntas militares autodenominada "Proceso de Reorganización Militar" (19761983). El informe de la Comisión Nacional sobre la Desaparición de Personas (CONADEP) conocido como Nunca más demostró el plan sistemático de tortura y desaparición forzada de personas. Como resultado del juicio se condenó en un fallo ejemplificador a Jorge Rafael Videla y Eduardo Massera a reclusión perpetua, y a otros civiles y militares a diversas penas por su participación criminal en la dictadura. En 1989, el recién electo presidente Carlos Saúl Menem indultó por decreto a civiles y militares a sus condenas por los delitos cometidos durante aquella dictadura. A partir de allí se inaugura un periodo de impunidad que dura 
hasta el año 2003, cuando se abren nuevamente las causas imprescriptibles contra delitos de lesa humanidad.

Más allá de los reclamos de justicia materializados en los diversos procesos legales, en Argentina existe un numeroso y variado archivo cinematográfico y documental sobre la última dictadura que da cuenta de otro ámbito de discusión. En efecto, incluso antes de que ésta finalice en el año 1983, varios proyectos audiovisuales se ocuparon del proceso que por aquél entonces finalizaba; por ejemplo, en clave de ficción La historia oficial (L. PUENZO 1984) o documentales como La república perdida (M. PÉREZ 1983). La perspectiva asumida por esas representaciones es fundamentalmente generalizadora y se concentra en mostrar la realidad del terror y el genocidio llevado a cabo por la dictadura.

Hemos de esperar a la década del 1990 para hallar un cambio de perspectiva en la problematización del pasado reciente, promovida en buena medida por el pasaje de la reivindicación de la memoria del ámbito jurídico a los medios de comunicación y la aparición de nuevos actores sociales dentro del debate sobre la construcción de la memoria social, tales como los hijos de desaparecidos (APREA 2010, p. 280). El documental que instaura una nueva visibilidad en torno a los acontecimientos límite ocurridos durante la última dictadura es Cazadores de utopías (BLAUSTEIN 1996) que junto con los tres tomos de La voluntad (ANGUITA; CAPARRÓS 1997) dan comienzo a un nuevo tratamiento de la memoria (SONDERÉGUER 2001; OBERTI; PITTALUNGA 2005). ${ }^{2}$ El filme de Blaustein, por ejemplo, exhibe por primera vez el testimonio de numerosos mandos intermedios de Montoneros y otros testigos relacionados con militantes de base. En este contexto, la recuperación de la memoria fuera del esquema explicativo oficial propuesto por la teoría de los "dos demonios" suponía dejar hablar a los ex militantes víctimas del terrorismo de Estado. ${ }^{3}$

La nueva visibilidad que se les otorga a los ex militantes promueve una perspectiva que había sido relegada del discurso de la memoria sobre la última dictadura argentina y que hasta entonces no formaba parte de la discusión. Se hace público el carácter militante de las víctimas del terrorismo de Estado y se lo pone en relación con las consecuencias políticas de la desaparición forzada de personas. En este sentido, en los testimonios de los militantes revolucionarios de los años 1970, se filtra la subjetividad de un colectivo, una voz específica dentro de la memoria social de la dictadura, y, al mismo tiempo, se presentan "hechos" a través de testimonios. Lejos de la cautela epistemológica de la historiografía, la apuesta de multiplicar los testimonios tanto sobre los mismos acontecimientos como sobre experiencias similares es un intento de asegurar la verosimilitud que sustenta la argumentación del relato.

Desde mediados de la década del 1990 se presenta una nueva intervención en el espacio público: la organización H.I.J.O.S (Hijos por la Identidad y la Justicia

\footnotetext{
2 Para María SONDERÉGUER (2001) Cazadores de utopías representa un hito dentro de la tradición del discurso de la memoria, en tanto hace visible la voz de los militantes de la década del 1970 en la Argentina. Un análisis de la polémica que tuvo lugar en 1997 en el diario Página 12 a propósito de este documental es: SONDERÉGUER; ROCO-CUZZI (1996).

3 Para un análisis crítico de la teoría de los dos demonios presente en el prólogo escrito por Ernesto Sábato al Nunca más, ver DRUCAROFF (2002).
} 
contra el Olvido y el Silencio) marca un punto de inflexión en la producción del discurso de la memoria a partir de la asunción de una perspectiva generacional. ${ }^{4}$ Aunque no todos los autores que pertenecen a esta generación tengan una filiación militante con dicha organización, comparten el "giro subjetivo" que ya estaba presente en la recuperación del pasado a partir del testimonio como fuente privilegiada, pero llevándolo hasta sus últimas consecuencias. ${ }^{5}$

El subjetivismo se acentúa en un particular uso del lenguaje que tiende un lazo entre la memoria personal y la memoria generacional. ${ }^{6}$ La producción discursiva a partir de diversos dispositivos como novelas, diarios, blogs, instalaciones, intervenciones urbanas, muestras fotográficas, filmes y documentales, privilegia, además, la imagen (AMADO 2009, p. 157). ${ }^{7}$ Los distintos dispositivos creados en torno al uso de imágenes - por ejemplo los usos de la fotografía a partir de los cuales convocan al padre o madre ausente - refuerzan el lazo genealógico trunco y les posibilitan un medio privilegiado de expresión.

El testimonio audiovisual también concentra buena parte de su poder persuasivo en la imagen. Establece una relación entre ésta y el mundo real que atestigua la presencia del realizador en el lugar de los hechos y promueve de esta manera la verosimilitud de lo representado. Sin embargo, en los documentales, la cualidad indicativa de la imagen, más que garantizar la autenticidad histórica, es una prueba del registro del mundo y un testimonio de la realidad del mismo proceso de registro. En este sentido, la imagen (sea una reconstrucción de acontecimientos pasados o un testimonio) se presenta a sí misma como representación no en el sentido de mimesis (como es el caso del realismo historiográfico) sino como un registro parcial y fragmentario de un aspecto del mundo.

En el caso de los hijos, sus propios testimonios, vicarios de la experiencia de sus padres, dan cuenta ya no de la desaparición o la tortura, sino de la extrema dureza de las condiciones de persecución, exilio, clandestinidad, etc., vividas durante su niñez. Al mismo tiempo, a menudo cuestionan los compromisos ideológicos de sus padres desde una posición afectiva antes que ideológica. Hay una presunción de que el testimonio o la voz de los hijos, en tanto proceden biológicamente de padres desaparecidos, posee un estatus epistemológico privilegiado. Puesto que este problema excede el marco del presente trabajo, no nos extenderemos aquí sobre el mismo. ${ }^{8}$ Sin embargo, es preciso decir que

\footnotetext{
${ }^{4}$ HIJOS ("Hijos por la Identidad y la Justicia contra el Olvido y el Silencio") hace sus primeras apariciones públicas a partir de los llamados "escraches" a los represores que se remontan al año 1996, aún cuando comienza a gestarse en 1994 en el marco de un homenaje a los desaparecidos de la Facultad de Arquitectura de La Plata.

${ }^{5}$ Es preciso aclarar que si hablamos de "generación" lo hacemos sólo en la medida en que es posible identificar ciertas características formales que prefiguran una modalidad discursiva y configuran una voz colectiva más o menos reconocible. De modo que no tomamos el término en un sentido biológico, sino más bien cultural o antropológico: "generación" es aquí el "conjunto de personas que por haber nacido en fechas próximas y recibido educación e influjos culturales y sociales semejantes, se comportan de manera afín o comparable en algunos sentidos" (RAE).

${ }^{6}$ Para el giro subjetivo y su relación con el discurso de la memoria en la Argentina ver: ARFUCH (2010) y SARLO (2005).

7 Aún en las novelas se intercalan fotos, a menudo intervenidas, en las que aparecen escenas familiares o cotidianas de las personas desaparecidas o de los hijos de aquellos cuando aún eran niños (por ejemplo en el Diario de una princesa montonera, de María Eva Pérez, 2012).

${ }^{8}$ La cuestión del estatus epistemológico del testimonio constituye un problema de difícil resolución para la
} 
si bien en todos estos documentales el testimonio es la fuente privilegiada para reconstruir los acontecimientos en cuestión, estos principalmente sirven para configurar una argumentación. Nos concentraremos, pues, en el uso de los testimonios dentro de la diégesis documental y no en la relación de su contenido con los acontecimientos testimoniados; o, en otras palabras, el objeto de nuestro análisis es la representación documental y la argumentación que esta supone, de la cual el testimonio es uno de sus elementos más destacados. ${ }^{9}$

De diversas maneras, el discurso de los hijos de desaparecidos pone en entredicho a la modalidad de discurso que los precede, tanto al denominado "discurso oficial" como al discurso elaborado por la militancia revolucionaria sobre la memoria traumática generada por la última dictadura argentina. Asumimos que toda narrativa o argumentación sobre el mundo histórico nos introduce en el ámbito de la ley, o en otras palabras, del statu quo. En la medida en que el autor o realizador es "consciente de sí mismo desde un punto de vista histórico", también lo es del "sistema social y de la ley que lo sustenta" (NICHOLS 1997, p. 247). En consecuencia, su interpretación de los acontecimientos representados estará guiada por una moralización sobre el orden social que rige en su contexto histórico y será elaborada para sostenerlo o impugnarlo. De modo que en las diversas modalidades del discurso de la memoria, aún cuando respondan a un mismo objeto discursivo, sus estilos, conceptos y temas serán distintos, en virtud de una toma de posición dentro del campo de prácticas de la memoria (jurídicas, conmemorativas, reivindicativas, identitarias, etc.) (FOUCAULT 1979, p. 33-104). En el caso de los hijos de desaparecidos, esta tensión entre las diversas modalidades del discurso de la memoria se presenta de un modo específico. Los hijos rechazan de plano el discurso oficial centrado primero en la teoría de los "dos demonios" y luego en los indultos para habilitar una reconstrucción del pasado reciente desde el punto de vista de la militancia y las consecuencias políticas de la dictadura. Pero a diferencia de quienes vivieron la dictadura como adultos, esta generación discute también con la que los precede a partir de la memoria intergeneracional (AMADO 2003, p. 58).

historiografía y las ciencias sociales. En el caso que nos ocupa, VEZZETTI (2002) y SARLO (2005) presentan una crítica epistemológica del testimonio que rescata su importancia política y ética, pero pone en duda su valor como una fuente para la historia y las ciencias sociales, al mismo tiempo que destacan su función indispensable en el ámbito jurídico. Pilar CALVEIRO (2008) rescata otra dimensión ínsita en el testimonio de experiencias límites, su capacidad de transmitir experiencias vitales únicas. En cualquier caso, la presunción de base es que la experiencia como fuente de conocimiento es la que otorga un privilegio epistémico al relato del testigo. Esteban Lythgoe traza el derrotero del testimonio en la epistemología occidental y su rol fundamental en el actual discurso de la memoria (LYTHGOE 2009). Una lectura sobre el testimonio que rechaza el privilegio epistémico del testigo y hace del testimonio un elemento constitutivo del pasado la hallamos en "The Epistemic and Moral Role of Testimony" (TOZZI 2012).

9 Hayden White ha realizado varios trabajos sobre el testimonio bajo la denominación de "Witness Literature", por ejemplo: "Realismo figural en la literatura testimonial" (WHITE 2010b) o "Discurso histórico y escritura literaria" (WHITE 2010c). En ellos, concentra su atención en los elementos figurativos o literarios presentes en los testimonios que arrojan un tipo de información diferente a la fáctica, es decir, informan sobre lo que sintió o experimentó el sobreviviente de situaciones límites. Pese a que sus análisis resultan sumamente valiosos para nuestra lectura, a diferencia del presente trabajo, que se concentra en la emergencia de la figura de hijo de desaparecido al nivel del discurso, en la que ésta se construye al interior de la diégesis documental, los análisis de White sobre la Witness Literature son pertinentes al nivel del enunciado, pero sin referencia a la verdad o falsedad de los mismos. 


\section{La figura de hijo de desaparecido}

En esta sección, discutiremos cómo se constituye la figura de "hijo de desaparecido". Esta figura responde a una apuesta estética en la medida en que, por una parte, en los trabajos de la generación de los hijos hallamos el uso de un particular estilo que expresa una voz autoral o perspectiva para representar aspectos del pasado reciente, $y$, por la otra, se emplean codificaciones que forman parte de una apuesta colectiva. Pero ésta representación también está guiada por una apuesta ético-política, en la medida en que cada una de las figuras de hijo de desaparecido adopta una particular posición respecto de la modalidad de discurso de la memoria que la precede y respecto de su propia generación. Así, el análisis de la constitución de la figura de hijo de desaparecido a partir del modelo estético que nos provee el figuralismo resulta provechoso para dar cuenta de la primacía de las dimensiones estética y ético-política sobre la epistemológica, en tanto que en estas representaciones del pasado reciente la figura de desaparecido se resignifica y se le otorga un nuevo sentido en función de aquella.

Huelga decir que la experiencia traumática que da origen a sus diversas figuraciones es la desaparición de sus padres en el marco de la última dictadura argentina. Estas comparten ciertas características que permiten generalizar una serie de motivos en común, entre los que se destacan la experiencia de la orfandad y la búsqueda identitaria. La emergencia de estos motivos no se debe tanto a que todos ellos forman parte de una misma generación, como a que comparten ciertos códigos de representación que suponen una confrontación con la codificación dominante en la modalidad del discurso de la memoria que inmediatamente los precede. Los realizadores se proponen a indagar sobre su propia identidad combinando distintas técnicas documentales afines con la reconstrucción histórica, especialmente la historia oral, pero desde un punto de vista subjetivo y subjetivizante. El realizador es, por así decir, sujeto y objeto de la indagación.

Consideraremos ahora el documental Papá Iván (2000) realizado por María Inés Roqué, hija de Julio Roqué dirigente de las FAR y Montoneros quien murió en un enfrentamiento con el ejército en 1977. Aquí la realizadora/hija intenta reconstruir los últimos años de la vida de su padre, especialmente los momentos previos a su muerte, dirigida por una pregunta que podríamos reconstruir así: ¿Quién fue realmente mi padre? Dice la realizadora en voice over: "cuando empecé a hacer esta película, sabía algunas cosas" [...] "lo que había oído que no era una descripción clara de los hechos, se convertía siempre en una imagen de una persona muy heroica" (Papá Iván 2000).

El pretérito utilizado en los verbos "empezar" y "saber" nos informa en el mismo inicio del documental que lo que se va a presentar a continuación es el resultado de algo que comenzó hace tiempo, de una investigación que ha modificado lo que el sujeto conocía antes, lo que "sabía". Eso que sabía se distingue, además, de los "hechos" (sean cuales sean estos), de aquello que informaba una figura paterna heroificada. Este "héroe" es el que es puesto en entredicho en el documental. Así es que, también al inicio del documental y asumiendo su rol de testigo, declara: "Yo una vez dije que prefería tener un 
padre vivo que un héroe muerto. Porque me pasé la vida en México, y las veces que fui a la Argentina, conociendo gente que me miraba [como] a la hija de un héroe" (Papá Iván 2000).

Desde el punto de vista de la argumentación, el documental comienza por el final, es decir por la conclusión. Solapa de esa manera el final de una narrativa de búsqueda y comprensión y la conclusión de una serie de argumentos que llevan a la autora a sentar las bases de una incertidumbre que es, a la vez, comienzo de la trama y resultado final de la investigación. Esta doble dimensión presente en el inicio del documental es importante, puesto que establece de una vez el tono de ambigüedad moral y epistemológica dominante en todo el filme. Para ello, comienza por poner en duda la figura heroica de su padre, eje a partir del cual pivotan todos lo demás argumentos.

A partir de aquí se suceden testimonios que pueblan al documental con diferentes voces y puntos de vista y construyen, de ese modo, la argumentación que sostiene en su representación del mundo. Los testimonios oscilan entre delinear un padre heroico y un padre que abandonó a su familia para realizar su misión revolucionaria. María Inés se asegura primero de cimentar las bases que construirán al héroe y luego las desmonta poco a poco. Si bien el héroe nunca desaparece, queda mellado en su impoluta integridad. De este modo, pone en discusión el discurso heroificante heredado, exhibido a través de más de una docena de testimonios que incluyen además de los compañeros de militancia de su padre, a amigos de la familia, a ex alumnas de Julio Roqué y a su propio hermano, el tío de María Inés. Para realizar completamente la figura del héroe también se requiere de su contracara, el villano, que en la narrativa de los militantes revolucionarios está dado en la figura del "traidor" (ZEITLER VARELA 2012). Así, presenta una entrevista a Miguel Bonasso que acusa a Miguel Ángel Laulleta de "entregar" (delatar) a Julio Roqué, e incluso de proponer un brindis por su muerte mientras se encontraba en cautiverio en la ESMA. La realizadora desmonta esta figura heroica comunicando en voice over sus ansiedades, expectativas y frustraciones como hija, y principalmente a partir del testimonio de su propia madre Azucena Rodríguez. Ella es la encargada de dar el contrapunto que desnuda la intimidad del hombre y humaniza al héroe. La técnica utilizada en todos los casos es la confrontación de puntos de vista a partir del uso de testimonios.

La prefiguración metafórica de la diégesis hace posible que la realizadora asuma el punto de vista del padre desde la perspectiva de la hija. Podría pensarse que al leer una carta de su padre, la hija le presta su voz bajo la figura de la prosopopeya. De hecho, en cierto sentido ese objeto inanimado que es la carta cobra vida y responde a las inquietudes de María Inés cuando ella la anima con su propia voz. Sin embargo, hemos preferido ver esta operación bajo la figura de la metáfora, puesto que lo que pone en evidencia es la irreconciliable tensión entre la perspectiva del padre y la de la hija a través de un elemento común cuyo significado se disputan: la figura del héroe. Antes que hacer hablar un objeto inanimado, lo que en realidad sucede es que hay dos elementos cuya semejanza no puede ocultar su diferencia. Así, la tensión entre el "Yo" de María Inés y el "Tú" 
de Iván no se resuelve nunca, y a través de la asunción de la voz del padre, la realizadora se permite cuestionarlo en el mismo esfuerzo de comprenderlo.

Es importante para el dispositivo que aún en la transfiguración que María Inés Roqué hace de las palabras de su padre se pueda distinguir la diferencia entre uno y otro. El uso de la voice over la habilita a asumir su propia voz y al mismo tiempo hacer hablar al padre a través de la lectura de la carta. Introduce en la argumentación del documental la perspectiva del padre interpelada por el comentario de la hija. De este modo, al finalizar el documental, cierra primero con un comentario de la realizadora y luego con la lectura del final de la misma carta. El comentario dice así:

Hice la película para entender por qué había hecho lo que había hecho y quién era en medio de todo eso ¿no?... y creo que más o menos lo entendí, pero siempre me va a quedar la pregunta de si se cuestionó en algún momento, aunque sepa que le dolía y aunque sepa que ahí está su pérdida, siempre me va a quedar la pregunta (Papá Iván 2000).

Con la voz entrecortada por el llanto, su última intervención como hija finaliza con una pregunta: ¿su padre alguna vez se cuestionó sus acciones? A continuación asume la voz de su padre, también por última vez, y contesta:

Bueno hijos, ahora que les he dicho esto me quedo más tranquilo y si me toca morir antes de volver a verlos estén seguros que caeré con dignidad y jamás tendrán que avergonzarse de mí. Pienso hacerle llegar esta carta a la mamá para que sea ella quien decida cuando pueden ustedes leerla. Ustedes la querrán mucho seguramente porque ella lo merece. Yo la quiero y la respeto mucho y siento todo el dolor que pueda haberle causado. Un gran abrazo y muchos besos de un papá desconsolado que no los olvida nunca, pero que no se arrepiente de lo que está haciendo. Ya saben, libres o muertos, jamás esclavos. Papá Iván (Papá Iván 2000).

Sin forzar mucho las cosas, podemos pensar figurativamente esta operación como consumando la figura heroica de Julio Roqué, heredada de un buen número de testimonios y relatos que provienen no sólo de sus compañeros de militancia, familiares y conocidos, sino también de individuos ligados al ejército, sus propios enemigos. Y esta consumación se realiza en la propia figura de la realizadora, en tanto hija de un héroe, o "hija de desaparecido". Introduce así una diferencia en la figura heredada y prefigura, a su vez, nuevos cumplimientos. Esta diferencia es justamente la perspectiva generacional y personal de la hija que excede el mero lazo biológico. Al discutir la figura heredada, la realizadora se permite interpretarla y elegir el modo en que esta figura la constituye identitariamente. Ya no se trata sólo de la abnegación y la entrega heroica, sino también de una evaluación de los daños y las pérdidas de semejante empresa.

Para terminar de calibrar nuestra sugerencia, podemos considerar un documental que en cierto sentido se halla en las antípodas del anterior. Los rubios (2003) de Albertina Carri es un filme difícil de clasificar. Como mínimo, podemos considerarlo como una ficción de la memoria y, a la vez, como un documental sobre 
la realización de dicha ficción. ${ }^{10}$ En cualquier caso, sostiene una argumentación sobre el mundo histórico, y los elementos ficcionales están puestos al servicio de dicha argumentación. El dispositivo desplegado en Los rubios satura la diégesis documental con la iteración del mismo mecanismo una y otra vez. Obsesivamente, la representación vuelve sobre sí misma mostrando su carácter construido. Cada intento de representación de la realidad es negado al desnudar el mecanismo mediante el cual la realidad se duplica en una representación.

El punto que el documental desea probar, a fuerza de repetición, se vuelve redundante. Las escenas son modulaciones de un mismo argumento: la actividad de la memoria es el olvido, recordar es inventar los objetos recordados. Antes que terminen los primeros once minutos del filme Analía Couceyro, la actriz que hace de Albertina Carri, escribe en un cuaderno el objetivo que persigue esta ficción documental: "exponer la memoria en su propio mecanismo. Al omitir, recuerda" (Los rubios 2003). Así es que cada uno de los recursos que se ponen en juego: repeticiones, multiplicación de representaciones, fragmentación y abolición del tiempo lineal, metalepsis, etc., intentan probar aquel punto.

Los rubios se inscribe de lleno en los temas y problemas característicos del discurso de la memoria. Discute con el discurso que tiene por centro la figura del "héroe", pero aún más con su propia generación, poniendo también en entredicho la figura del "hijo". No se trata de un conflicto generacional en el cual la vanguardia de la nueva generación asume una actitud beligerante contra los representantes del pasado inmediato, como sugirió Ortega y Gasset en su "La idea de la generación" (ORTEGA y GASSET 1964, p. 29-42). Si el documental que analizamos previamente discutía la figura del "héroe" y constituía no sin dificultad su doble, la figura del "hijo", ahora esta última también es puesta en discusión. Y lo hace orientando la atención del público sobre los códigos y los modos de presentación que hacen posible que surja el conflicto generacional. La estrategia desplegada por Carri no necesita discutir con un "otro" encarnado en tal y cual fulano, y no lo hace. Más bien desnuda las condiciones que hacen posible que un Roberto Carri, su padre, sea considerado un héroe, pero más importante aún, las condiciones que posibilitan que Albertina Carri se invista del privilegio epistémico que la habilitaría a proferir cierto tipo de verdades sobre el pasado de marras. Como cualquier otra persona, la realizadora puede hablar sobre su pasado, y cuando lo hace desde esa especial partícula del lenguaje que es el "yo", enseguida se inviste con una máscara, utiliza la prosopopeya. Su estrategia es tanto poner al descubierto los elementos que constituyen la máscara, como constituirse a sí misma a través de ello. Albertina Carri la desmitificadora: esa es su máscara.

¿Pero quiere decir esto que todo es un juego de apariencias, inane, poco serio? ¿Es un ataque contra la dignidad de la memoria y una frivolidad inadecuada a la importancia del tema?

\footnotetext{
${ }_{10}$ En este sentido, como es el caso de las docuficciones en general, Los rubios utiliza recursos abiertamente ficcionales para referirse al mismo ámbito de discusión que otros documentales, digamos, tradicionales. La tradición del realismo documental, como la historiografía, está dominada por las convenciones estéticas del realismo decimonónico. Ambas se dirigen al mundo y no crean un mundo como la ficción. A diferencia de la historia, el documental reconoce su naturaleza ficcional y esta no es una objeción contra sus pretensiones de referirse al mundo histórico e intervenir en él (NICHOLS 1997, p. 149).
} 
En primer lugar, la redefinición de los términos en los cuales se plantea la cuestión de la memoria es el tema sustantivo de la modalidad discursiva adoptada por los hijos. Carri adopta una actitud irónica respecto de la distancia que los hijos guardan con la modalidad de discurso que los precede (actitud que, considerada globalmente, también es irónica). En segundo lugar, la apuesta estética y política de Los rubios no se deja apresar en fáciles dicotomías, como aquellas que surgen de la más tradicional de todas: realidad o apariencia. En otras palabras, no se trata de tensionar al máximo la apariencia y la superficialidad para negar los derechos sustantivos de lo real. Se trata de adherir a una ontología constructivista dentro de la cual lo real es coproducido por el sujeto, donde la producción de "lo real" incluye al mismo sujeto. No hay ninguna novedad en esta tesis; en cualquier caso, la originalidad de la realizadora es llevarla a un ámbito donde aún dominan demasiados prejuicios respecto de lo que es real o debería serlo.

La reflexividad en Los rubios transgrede las convenciones adoptadas por la modalidad discursiva de los hijos. Si en Papá Iván emerge un "yo" opuesto a un "tu", en Los rubios el "yo" se opone al "nosotros" de los hijos. Los rubios discute con la generación anterior y sus modos de presentación sólo en la medida en que primero discute con los miembros de su propia generación, quienes asumen una identidad en conflicto con la que los precede. Por eso, principalmente cuestiona la codificación utilizada por la modalidad discursiva de los hijos.

A pocos minutos de comenzar el filme, Analía Couceyro se presenta como 198 la actriz que va actuar de Albertina Carri. Podemos ver en el desdoblamiento que Carri hace de sí misma un llamado de atención al espectador sobre la representación más que sobre lo representado. Si bien es posible atribuirle a la autora la composición de la escena, en realidad es Couceyro en su calidad de actriz la que desnuda el dispositivo. La representación de la realidad presupuesta por cualquier documental en este caso se fija sobre Couceyro-actriz que va a representar a Albertina Carri. De esta manera, Carri directora introduce oblicuamente su perspectiva en la diégesis documental generando una meta-diégesis en la cual Couceyro se presenta como Carri en tanto hija de desaparecidos. En otras palabras, la ficción documental introduce dentro de sí misma otra ficción, promoviendo algo así como una ficción en segundo grado (como Sheherezade, cuando le relata al rey un cuento cada noche e introduce una narración dentro de la narración). En el proceso, produce una transgresión de los límites fijados a la ficción documental que Gerard Genette denomina "metalepsis" (GENETTE 2004). Esta transgresión hace visible el carácter artefactual de la representación de la realidad en el documental, puesto que lo que la cámara registra es la ficcionalidad misma, la construcción del personaje ficcional que, en este caso, asume la identidad de Albertina Carri. Esta es una manera de exponer el funcionamiento del particular mecanismo memorialístico desplegado en las representaciones de los hijos de desaparecidos.

Otro ejemplo del mecanismo de la memoria según la consideración del olvido como una fuerza activa y el recuerdo como invención: una entrevistada por la producción de Los rubios rememora detalles sobre los Carri, sus vecinos 
de la segunda mitad de los años 1970. Vale aclarar que Albertina Carri nunca se presenta como una de las hijas de sus antiguos vecinos, de modo que la entrevistada desconoce de quien se trata. La vecina declara que en la casa de al lado donde vivían los Carri se escuchaba hasta las tres de la mañana el sonido de lo que parecía una máquina de escribir, que eran buenos vecinos, simpáticos, que la mujer era delgada, que todos en la familia eran rubios: el padre, la madre y las tres nenas. Sin embargo, ni Albertina ni ninguno de sus familiares es o era rubio.

¿Qué pensar de esta confusión, de este malentendido? ¿Es una comprobación más de que la memoria es una facultad engañosa para recolectar información? ¿Esta equivocación final desestima el resto de la información, por caso el sonido de la maquina de escribir hasta las tres de la mañana? ¿Quiénes son los rubios, cómo entender este fallido? Podríamos pensar que para la memoria es tan significativo lo que olvida como lo que recuerda. La hipótesis del mismo filme es que en un barrio popular del conurbano bonaerense en la segunda mitad de los años 1970, la familia Carri desencajaba. Se notaba, como también se nota en el registro de la entrevista, que gente como Carri no pertenece al barrio (o al menos eso es lo que se deja entrever en el documental cuando el equipo de filmación con sus aparatos y sus preguntas parece alterar la normalidad del barrio). En lenguaje llano, son rubios en una comunidad de morochos. ¿Pero acaso esto no es también significativo? ¿Deberíamos ver en la representación de este testimonio sólo un rechazo a las pretensiones de verdad del testimonio en general? La incorporación de esta entrevista puede leerse también como una muestra de que el equívoco que le da título al filme no forma parte simplemente de un juego irónico. Así, inmediatamente después de estas declaraciones y mientras Couceyro/Carri grita una y otra vez en un parque, en voice over se pregunta por la razones que tuvo su madre para no irse del país. Dice:

Me cuesta entender la elección de mi mamá. Por qué no se fue del país, me pregunto una y otra vez. O a veces me pregunto por qué me dejó aquí en el mundo de los vivos. Y cuando llego a esta pregunta me revuelve la ira. Y recuerdo, o eso creo, a Roberto, mi padre, y su ira o su labor incansable hasta la muerte (Los rubios 2003).

Este tipo de preguntas sitúan a Los rubios dentro de los problemas planteados por los hijos de desaparecidos. Además, ¿el sonido de la máquina de escribir no se relaciona también con la "labor incansable" de su padre? ¿Y su madre rubia en tierra de morochos no elige acaso estar donde no debería? Estas otras preguntas, personales y a la vez sobrecodificadas por la modalidad discursiva de los hijos, también son evocadas cuando por contigüidad se relaciona el monólogo de Carri al equívoco testimonio de la vecina que inmediatamente lo precede.

La ironía de Los rubios cobra pleno sentido en cuando advertimos que se halla tanto dentro de los temas y problemas planteados por el discurso de los hijos, como también fuera de ellos en la medida que su propia intervención supone la suspensión de dichos temas y problemas y el desvío hacia otro modo de considerar la memoria. De hecho, en simultáneo con el efecto de extrañamiento que promueve su representación, Carri postula una memoria 
individual distinta de la memoria social. El final de Los rubios es particularmente elocuente en este sentido. Después de la entrevista con la vecina que menciona a los rubios y del grito con el monólogo en voice over, hay una escena en la que Analía Couceyro compra pelucas rubias que terminan en las cabezas de todos los integrantes del equipo de filmación. En un camino de campo, el equipo de Los rubios se dirige hacia el horizonte y cada uno lleva puesto una peluca rubia. El campo del tío paterno es el lugar donde se refugiaron Albertina y sus hermanas después de la desaparición de sus padres. Es el lugar de la niñez de Albertina. El filme comienza con escenas de este mismo campo y termina con ellas. Sin embargo, el campo se repite con una diferencia. En el proceso de realización del filme, los miembros del equipo se volvieron rubios, igual que la familia Carri imaginada por la vecina. Al final del proceso de realización del filme y luego de deconstruir distintos dispositivos que aseguran la verosimilitud de la representación de la realidad en los documentales de la memoria, Carri finalmente consuma irónicamente la figura de hija de desaparecidos a través de una declaración audiovisual: la elección de su nueva familia y de un "nosotros" que excluye a aquél otro construido por los hijos de desaparecidos. En este punto, introduce una importante diferencia. La consumación de esta figura se da en franca discusión de los códigos de representación utilizados por otras representaciones pertenecientes a esta generación. Así, al mismo tiempo que realiza su propia figura de autora-hija de desaparecidos, problematiza la realidad de la representación ínsita en esta misma figura.

\section{A modo de conclusión}

En este trabajo, hemos sugerido que el modelo estético que nos provee el figuralismo nos permite relacionar acontecimientos y estados de cosas según el esquema de la figura y su cumplimiento. Bajo este supuesto, analizamos dos documentales realizados por hijos de desaparecidos en los cuales hemos podido observar que la constitución de la figura de hijo de desaparecido se realiza retrospectivamente a través del cumplimiento de la figura de desaparecido. No se trata tanto del lazo biológico que liga padres a hijos como de un tipo de relación construida por medios estéticos que involucra una toma de posición ético-política específica y distinta en cada caso. Así, en Papá Iván, la realización de la figura de hija supone la resignificación directa de la figura heroica del padre, mientras en Los rubios la realización de la figura de hija supone la resignificación de todo el ámbito de discusión, incluyendo fundamentalmente a los códigos aceptados por su propia generación para intervenir en el discurso de la memoria.

En ambos casos, la intervención y resignificación también dota de un sentido propio a los elementos simbólicos disputados. Si bien lo que está en juego es cierta interpretación del pasado, la disputa y lo disputado se hallan en el presente. El figuralismo pone en evidencia que el pasado disputado se constituye en la misma disputa. Y en este caso particular, la subjetividad del intérprete (el hijo) se constituye como resultado de esta misma interpretación. Más allá de las bases fácticas requeridas por la historia profesional o los tribunales, esta otra forma de reparación de la injusticia pasada privilegia los 
recursos estéticos para poner al pasado al servicio del presente. O mejor aún, para elaborar simbólicamente aquellos aspectos del pasado que están vivos en el presente.

\section{Referencias bibliográficas}

AMADO, Ana. Ficciones críticas de la memoria. Pensamiento de los confines, no 13. Buenos Aires: Fondo de Cultura Económica, 2003, pp. 55-64.

La imagen justa, cine argentino y política (1980-2007). Buenos Aires: Colihue, 2009.

APREA, Gustavo. El ciclo de los documentales sobre la izquierda revolucionaria peronista como testimonio y la discusión sobre la memoria social. In: MOGUILLANSKY, Marina y otros (comp.), Teorías y prácticas audiovisuales. Buenos Aires: Teseo, 2010, p. 277-290.

ARFUCH, Leonor. La entrevista, una invención dialógica. Buenos Aires: Paidós, 2010.

AUERBACH, Erich: Figura. Madrid: Editorial Trotta, 1998.

BEVERNAGE, Berber. Tiempo, presencia e injusticia histórica. In: MACÓN, Cecilia; CUCCHI, Laura (comp.), Mapas de la transición. Buenos Aires: Ladosur, 2010, pp. 169-188.

CALVEIRO, Pilar. Poder y desaparición: los campos de concentración en la Argentina. Buenos Aires: Colihue, 2008.

DRUCAROFF, Elsa. Por algo fue. Análisis del prólogo al Nunca más de Ernesto Sábato. Tres Galgos, n. 3, Noviembre, Buenos Aires, 2002.

FOUCAULT, Michel. La arqueología del saber. Buenos Aires: Siglo XXI editores, 1979.

GENETTE, Gerard. Metalepsis: De la figura a la ficción. Buenos Aires: Fondo de Cultura Económica, 2004.

LACAPRA, Dominick. Escribir la historia, escribir el trauma. Buenos Aires: Nueva Visión, 2005.

LYTHGOE, Esteban. Testigo; testimonio. In: BRAUER, Daniel (comp.) La historia desde la teoría. Vol. 2. Buenos Aires: Prometeo, 2009, p. 213-224.

MACÓN, Cecilia. Pensar la democracia, imaginar la transición. Buenos Aires: Ladosur, 2006.

NICHOLS, Bill. La representación de la realidad: Cuestiones y conceptos sobre el documental. Barcelona: Paidós, 1997.

OBERTI, Alejandra; PITTALUNGA, Roberto. Temas para una agenda de debate en torno al pasado reciente. Políticas de la Memoria, n. 5. Verano 2004/2005, CeDinCi, 2005, p. 9-14.

ORTEGA y GASSET. Obras completas. Vol. V (1933-1941). Madrid Biblioteca de Occidente, 1964. 
SONDERÉGUER, María. Los relatos sobre el pasado reciente en Argentina: Una política de la memoria. Revista Iberoamericana, n. 1 (segunda etapa) América Latina-España-Portugal, Madrid, 2001.

; ROCO-CUZZI, Renata. Miradas sobre los '70: Una polémica 20 años después. Revista de Literatura, n. 32, 1996, p. 151-157.

TRAVERSO, Enzo. El pasado, instrucciones de uso. Buenos Aires: Prometeo, 2011.

TOZZI, Verónica. The Epistemic and Moral Role of Testimony. History and Theory, v. 51 , n. 1, 2012, p. 1-17.

Posguerra, Realismo Figural y nostalgia. Signos filosóficos, v. X, n. 19, 2008, p. 115-144.

VEZZETTI, Hugo. Pasado presente. Buenos Aires: Siglo XXI, 2009.

WHITE, Hayden. La historia literaria de Auerbach. Causalidad figural e historicismo modernista. In: Ficción histórica, Historia ficcional y realidad histórica. Buenos Aires: Prometeo, 2010a [1996], p. 33-52.

- Realismo figural en la literatura testimonial. In: Ficción histórica, Historia ficcional y realidad histórica. Buenos Aires: Prometeo, 2010b [2006], p. 183-202.

. Discurso histórico y escritura literaria. In: Ficción histórica,

202 Historia ficcional y realidad histórica, Buenos Aires: Prometeo, 2010c [2004], pp. 203-216.

. ¿Qué es un sistema histórico? In: La ficción de la narrativa:

Ensayos sobre historia, literatura y teoría, 1957-2007. Buenos Aires: Eterna Cadencia, 2011, p. 251-264.

ZEITLER VARELA, Mariela. Dictadura y traición: relatos de la sobrevivencia desde el documental Montoneros, una historia. Revista Taller (Segunda Época): Sociedad, Cultura y Política en América Latina, Vol. 1, no 1, Octubre, 2012, p. 250-262.

\section{Películas}

Papá Iván dirigida por María Inés Roque. México, Argentina, 2000. Duración: 55 minutos.

Los rubios dirigida por Albertina Carri. Argentina, 2003. Duración: 89 minutos. 